\title{
Measuring cultured fish swimming behaviour: first results on rainbow trout using acoustic telemetry in tanks
}

\author{
Marie-Laure Bégout Anras* and Jean Paul Lagardère
}

Centre de Recherche sur les Ecosystèmes Marins et Aquacoles, CNRS/IFREMER, B.P. 5, 17137 L'Houmeau, France

*: Corresponding author : Phone : 335465006 95; fax : 33546500600 E-mail address: mlbegout@ifremer.fr

\begin{abstract}
:
An experiment was conducted to measure swimming activity of rainbow trout $(254.0 \pm 33.7 \mathrm{~g})$ held in outdoor tanks under three culture conditions with stocking density used to generate differences: 27 (Culture Density 1, CD1), 80 (CD2) and $136 \mathrm{~kg} \mathrm{~m}^{-3}$ (CD3). Fish were fed dry pellets at $1 \%$ of tank biomass from $9 \mathrm{~h} 00$ to $13 \mathrm{~h} 00$ with automatic feeders. Using acoustic telemetry, fish positions were monitored every $5 \mathrm{~s}$ during $48 \mathrm{~h}$ for nine fish (three in each treatment). Swimming behaviour was analysed in terms of trajectories: they varied between (i) holding position (high turning angles), (ii) chaotic trajectories (equal use of all turning angles) and (iii) circular swimming (average turning angle of $\left.60^{\circ}\right)$. Space utilisation differed for each culture condition: CD3 conditions induced a prolonged residence time in the central zone of the tank. Rainbow trout swimming activity patterns and levels differed depending on both day-night alternation and culture conditions. All fish reared at CD1 and one reared at CD2 were day-active. All the other fish showed high activity pattern variability and a higher swimming level was observed under CD3. These results illustrate that monitoring fish swimming activity is feasible even under high densities and provide relevant insights on fish activity which can lead to behavioural welfare indices in relation to constraints imposed by culture conditions.
\end{abstract}




\section{Introduction}

When an animal is exposed to a perturbation, the first line of defence is a behavioural one, most often an avoidance behaviour, designed to lessen the probability of death or the metabolic costs incurred by maintaining physiological homeostasis (Olla et al., 1980; Schreck et al., 1997). Such behavioural alterations are very sensitive indicators of a constraint level or stress imposed on fish by the environment (Schreck, 1990; Scherer, 1992; Cooke et al., 2000).

Under aquaculture, multiple constraints are imposed on fish and the assessment of the behaviour of cultured fish has always been difficult due to the timing of sampling, differences between experimental and aquaculture conditions and to methodological bias arising from repeated fish handling (Baras and Lagardère, 1995). Biotelemetry techniques offer a wide range of possibilities to improve both production and management in aquaculture through monitoring of behaviour or physiology of free-swimming fish inside their culture environment. Indeed, knowing how key parameters are changing, can allow faster adjustment of feeding times to activity rhythms, more objective identification of the preference/tolerance margins towards environmental variables and precise assessment (from 'the fish's point of view') of the impact of environmental or operational stressors on fish (Baras and Lagardère, 1995). In the case of long lasting stressors induced by culture density such as crowding, avoidance or behavioural mitigation may not be possible and induced changes in behaviour may then reflect deleterious changes in how an animal senses and responds to its environment. Significant departures from behavioural norms would then be suggestive of a decreased probability of survival (Schreck et al., 1997).

In this context, our focus was placed on swimming behaviour with variables such as trajectory complexity, spatial distribution, activity rhythm and level examined for a highly selected strain of rainbow trout (Oncorhynchus mykiss, (Walbaum)) raised under three culture conditions characterised by increasing densities $\left(27,80\right.$ and $\left.136 \mathrm{~kg} \mathrm{~m}^{-3}\right)$. Swimming activity was measured using an acoustic positioning telemetry system (Lagardère et al., 1990; Bégout Anras et al., 1997; Bégout Anras and Lagardère, 1998). Our objectives were (i) to identify the activity variables altered by culture conditions, (ii) to quantify such alterations and (iii) to contribute to the definition of cultured fish well-being since, following Dantzer (1995), and Ellis et al. (2002) 
one can suppose that the identification of constraints imposed by rearing environment on behaviour constitutes an unbiased initial step in searching for discomfort factors.

\section{Materials and methods}

Experiments were conducted in 1999 at an experimental fish farm (Salmoniculture Expérimentale Marine IFREMER-INRA, Sizun, France, $\left.48^{\circ} 24^{\prime} \mathrm{N}, 4^{\circ} 4^{\prime} \mathrm{W}\right)$.

Ten month old rainbow trout (INRA spring strain) were raised for three months (December to February) at three initial culture densities : 25,75 and $125 \mathrm{~kg} \mathrm{~m}^{-3}$ in circular outdoor tanks ( $\varnothing 2 \mathrm{~m})$. In March, fish were randomly sampled from each of the culture densities and placed in 3 similar outdoor tanks with respect to their previous rearing density (Table 1). Behavioural recording started two weeks after transfer with fish weighing $254.0 \pm 33.7 \mathrm{~g}$ and initial densities set at 27, 80 and $136 \mathrm{~kg} \cdot \mathrm{m}^{-3}$ (CD1, CD2, CD3 respectively).

Table 1 : Experimental conditions in circular tanks $\left(\varnothing 2 \mathrm{~m}, 0.94 \mathrm{~m}^{3}\right)$.

\begin{tabular}{lccc} 
& \multicolumn{3}{c}{ Culture condition } \\
& CD1 & CD2 & CD3 \\
\hline Number of fish & 116 & 333 & 583 \\
Final total weight $(\mathrm{kg})$ & 29 & 85 & 145 \\
Mean weight $(\mathrm{g} \pm \mathrm{SD})$ & $251 \pm 47.2$ & $256 \pm 66.3$ & $249 \pm 57.3$ \\
Flow rate $\left(\mathrm{m}^{3} \mathrm{~h}^{-1}\right)$ & 0.8 & 2.4 & 4.0 \\
\hline
\end{tabular}

The tanks were supplied with $11^{\circ} \mathrm{C}$ aerated fresh water diverted from a nearby spring. Water level was set to $30 \mathrm{~cm}$ in each tank $\left(0.94 \mathrm{~m}^{3}\right)$ and water renewal flow was calculated to make water quality conditions uniform by adjusting water renewal proportional to each culture density (Table 1). Water inflow was slightly directed against the tank wall to reduce acoustic noises and tanks drained at the centre. Tanks were covered with a solid top partially open on one half side (Fig. 1). Water inflow and outflow and automatic feeder positions differed between 
tanks due to the original layout of the experimental farm that could not be altered for this experiment.

\ Hydrophone

Water inflow

Water outflow

Automatic Feeder

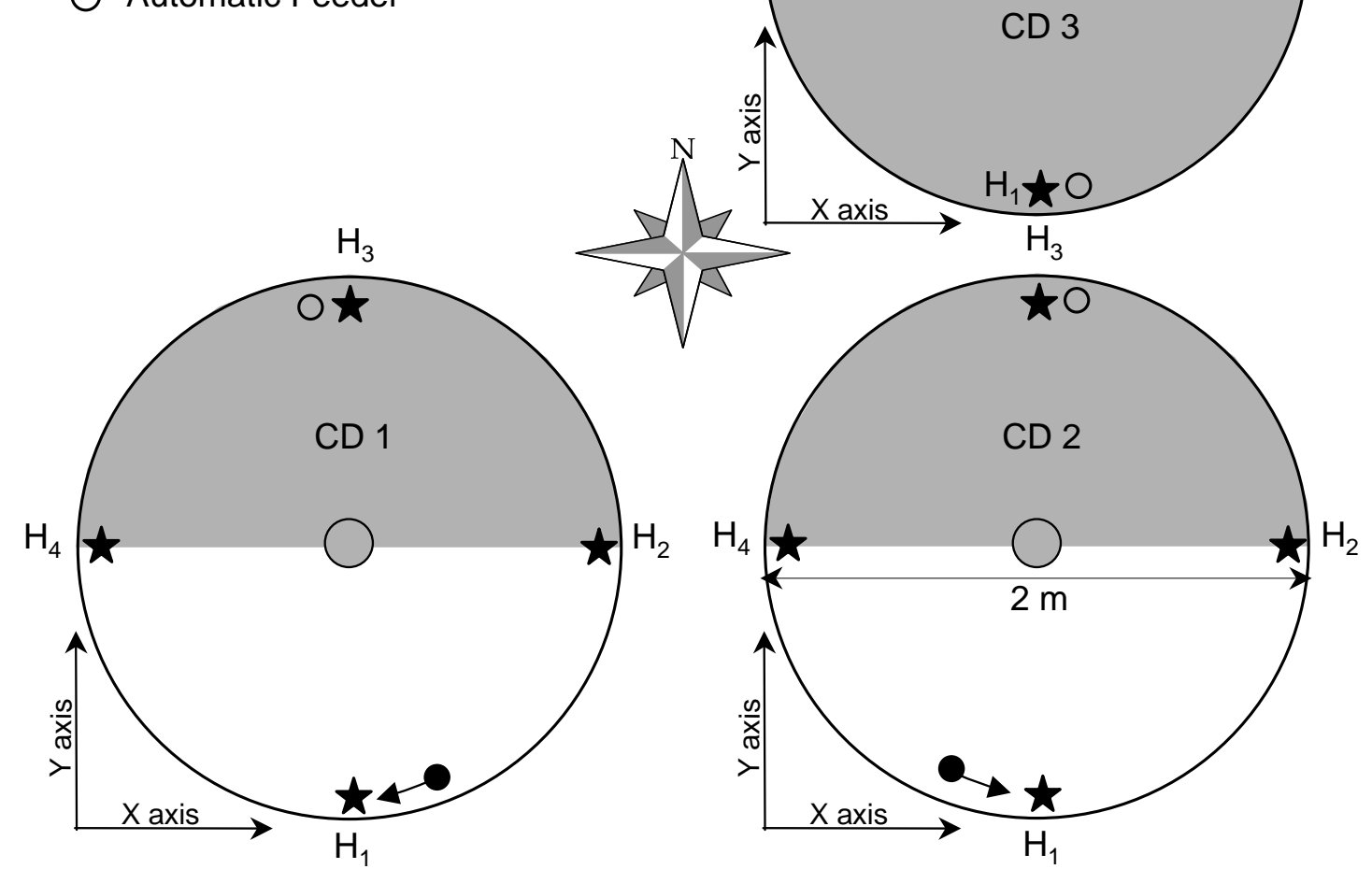

Figure 1 : Experimental set-up : tanks were covered with a solid top and half of this top was partially open to allow light to enter the tank (grey shading illustrate the totally closed half). Water inflow and outflow and automatic feeder positions differed between tanks. The acoustic position system composed of four hydrophones $(\star)$ was installed in the same manner in each tank, giving the same orientation to the ordinate axes.

Before and during the experiment, fish were maintained under natural photoperiod (approximately L:D 12:12). They were fed dry pellets at $1 \%$ body-weight daily ration by automatic feeders which regularly distributed the food (one meal every $10 \mathrm{~min}$ ). Numbers of 
pellets distributed during each meal were adjusted for each culture condition to make sure that all food was given over a four hour period starting at 9h00 (UT+1).

Nine fish were randomly chosen to perform behavioural recordings of $48 \mathrm{~h}$ duration : three fish were tracked in each culture condition (CD1, CD2 and CD3) providing pseudoreplicates when true replication was not available to us.

The fish were fitted with an ultrasonic transmitter under light anaesthesia in oxygenated water containing 2-Phenoxyethanol $\left(0.2 \mathrm{ml}^{-1}\right)$. The transmitter (V8SC-1L; Vemco Ltd, $4 \mathrm{~g}$ in air) was externally attached close to the dorsal fin using two kevlar monofilament sutures with a plastic pad retaining the tag on the opposite side (illustrated in Bridger \& Booth, 2003) following the recommendations of Ross and McCormick (1981) concerning the tag weight to fish weight ratio $<2 \%$. After recovery from anaesthesia in aerated water, the fish were released and allowed to recover for 3 days before recording started. Some direct and video observations confirmed that untagged and tagged fish displayed the same behavioural patterns.

The system comprised a miniature ultrasonic transmitter and a receiving antenna of four spatially separated hydrophones (Brüel \& Kjaer, type 8104) with associated preamplifiers (Brüel \& Kjaer, type 2634), (Fig. 1). The arrival time differences of the signals amplified by four automatic high dynamic gain amplifiers were measured by the time-counter calculation channel with an accuracy of $1 \mu \mathrm{s}$. Specially developed software, LOCA 62 was used to interrogate the time-counter calculation channel at regular intervals of $5 \mathrm{~s}$, recording the arrival time differences as well as date and time. The measure of the arrival time of the acoustic signal to three of the four hydrophones supplied the information to calculate by triangulation the position of the fish using the trajectography software TRACKBAR (GISTEM-CREMA L'Houmeau, Lagardère et al., 1990). This system allowed position determination every $5 \mathrm{~s}$ of one single fish at a time with an accuracy of $<10 \mathrm{~cm}$ enabling calculation of distance between consecutive fixes integrated per hour. Turning angles were defined as the angle between the projection of the two lines joining three consecutive positions by pairs (formula given in Tang and Boisclair, 1993), calculated with 
values varying between 0 and 180 degrees chosen to identify simplified swimming directions. Swimming trajectories were also plotted graphically.

Turning angles for day-time swimming activity recordings were randomly sub-sampled to give 800 values per fish ( 5 to $10 \%$ of the original data set) in order to perform statistical analysis. Turning angles data set followed normality rules and were compared among fish using parametric one factor analysis of variance and Tukey HSD multiple comparison tests.

Space use analyses were realised by integrating position data into a G.I.S. software (Idrisi32, Clark Labs, USA). Tanks were divided in 13 equal surface sectors $\left(0.27 \mathrm{~m}^{2}\right)$ corresponding to three concentric circles (outer, medium and inner circle, Fig. 2). Residence frequencies in sectors and in the three circles were calculated for both day-time and night-time periods for each fish. Kruskal-Wallis non-parametric analysis of variance was performed to determine the effects of culture conditions on space use pattern.

The temporal distribution of swimming activity during the day was evaluated by calculating the daily activity pattern (Baras, 1992). This was done by averaging hourly distance moved for each of the four components of a day $(T U+1)$ : day-time during feeding (9h00 to 13h00), day-time without feeding (7h00-8h00, 13h00-18h00), night-time (20h00 to 5h00) and twilight (6h00, one hour before dawn, and $19 \mathrm{~h} 00$ one hour before dusk). Activity patterns were calculated for each nine $48 \mathrm{~h}$ behavioural recordings.

Activity patterns were analysed as follows. Non parametric Kruskal-Wallis analyses of variance were performed for the following comparisons : (i) activity levels between day-time during feeding and day-time without feeding were compared for each fish, (ii) activity levels between day-time, twilight and night-time were compared for each fish. Kruskal Wallis tests were considered significant when $\mathrm{P}_{\mathrm{kW}}<0.05$. All statistical analysis were performed using Systat (B) 7.0 for Windows. 

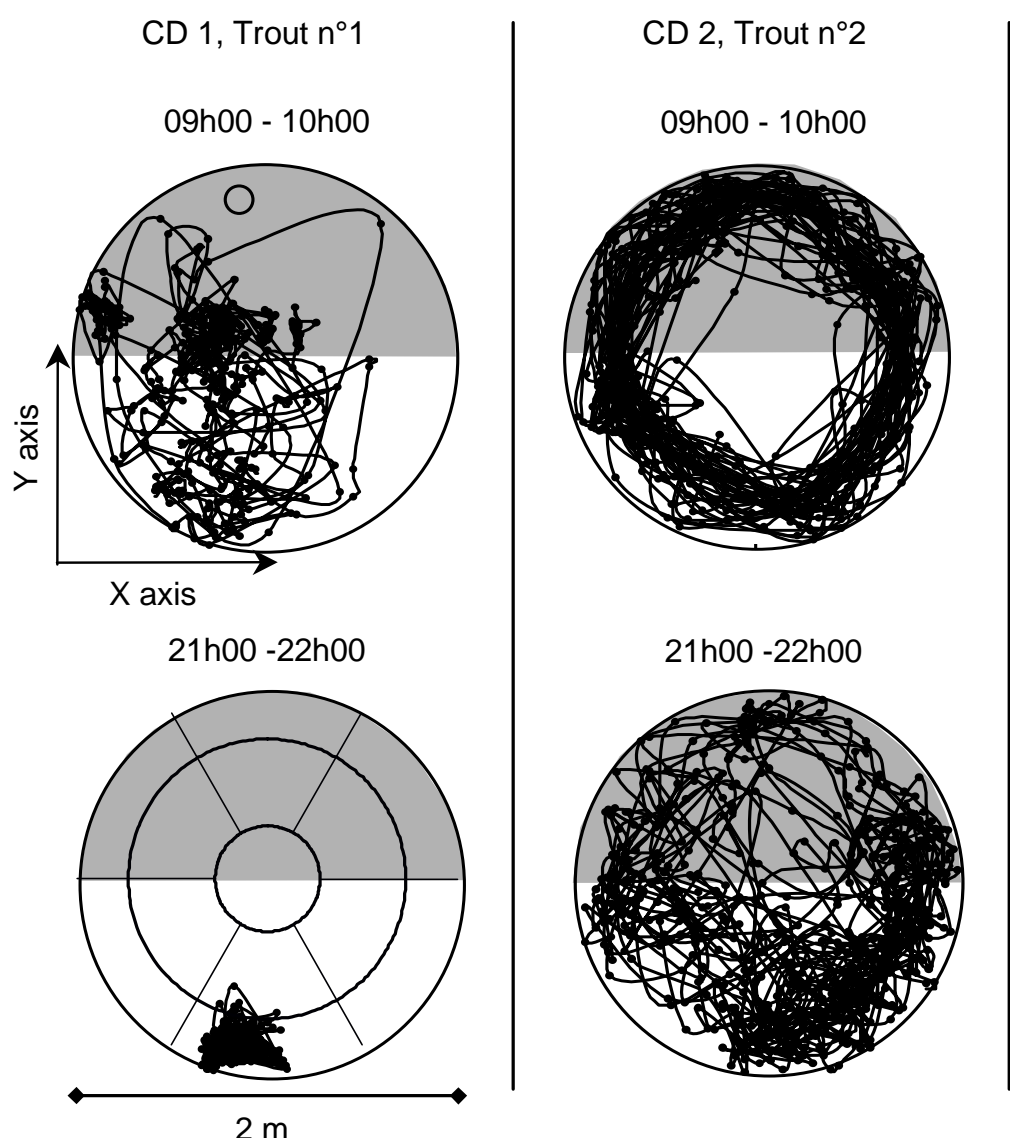

CD 3, Trout $n^{\circ} 2$
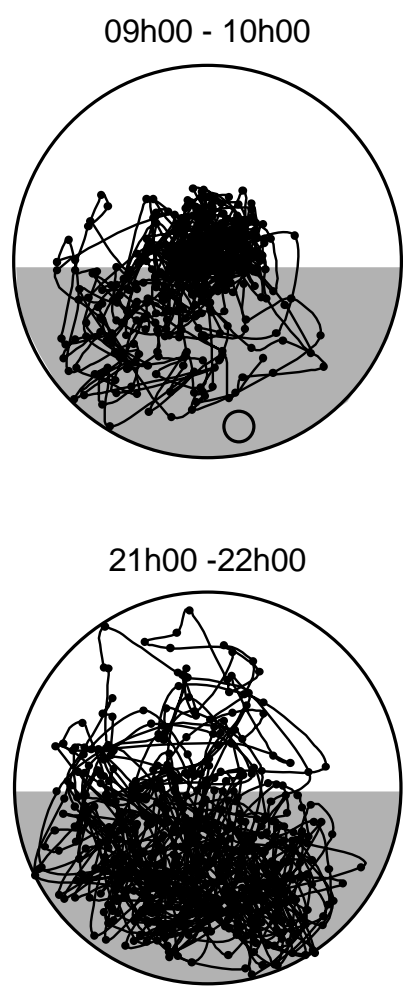

Figure 2 : Representative examples of one hour swimming tracks from 09h00-10h00 and from $21 \mathrm{~h} 00-22 \mathrm{~h} 00$ for one individual monitored under each culture condition (CD1, CD2 and CD3). The subdivision in equal surface sectors and in three concentric circles is shown in the lower left panel.

\section{Results}

\subsection{Swimming trajectories}

Rainbow trout swimming trajectories monitored under the 3 conditions appeared distinct. A representative sub sample of trajectory plots was selected for illustration purposes (Fig. 2). Under CD1, low amplitude movements were observed during the day and fish were stationary at night. Under CD2, one fish adopted a circular swimming pattern and its distribution covered most of the available space. However, this pattern was not apparent during night-time and was not observed for trout $n^{\circ} 3$ which showed similar movements as fish in CD1. Under CD3, fish movements appeared random and disorganised; space occupation was maximal, including the central zone where the tank drained. 


\subsection{Turning angles}

Analysis of variance showed that day-time turning angles differed among fish $\left(F_{(2,8)}=84.91, P<0.001\right)$ and Tukey HSD multiple comparisons showed that fish turning angles were grouped in 3 sets (Fig. 3). The 3 trout of $C D 1$ and trout $n^{\circ} 3$ of $C D 2$ belonged to a first group characterised by high turning angles, corresponding to a fish that was drifting and holding position and being predominantly stationary. Trout $\mathrm{n}^{\circ} 1$ from $\mathrm{CD} 2$ and all 3 trout from CD3 formed a second group characterised by an average turning angle around $90^{\circ}$. Trout $n^{\circ} 2$ from CD2 had a distinct average turning angle around $60^{\circ}$ associated with a circular swimming pattern (Fig. 2 \& 3).

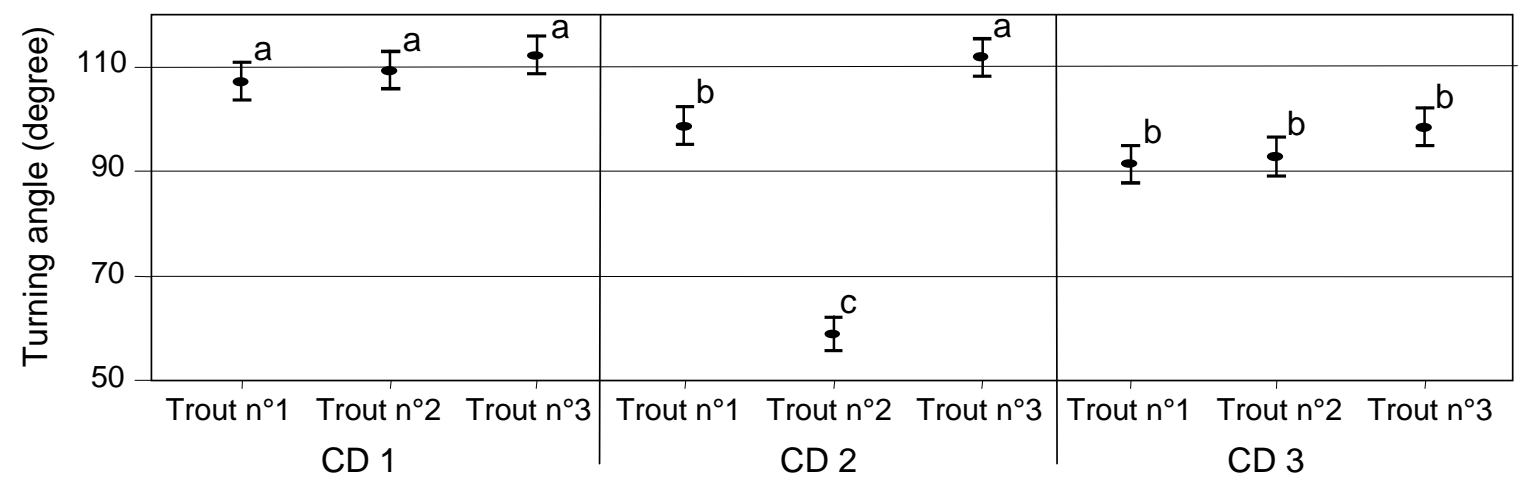

Figure 3 : Average turning angle and standard deviation calculated for each fish in each culture condition (CD1, CD2, CD3) for day-time swimming activity recordings. Significant differences are indicated by different letters.

\subsection{Space utilisation}

Statistical analysis of space utilisation, i.e. the distribution per sector, showed that residence frequencies significantly differed between culture conditions $(K W=15.54, d f=2$, $\mathrm{P}<0.001)$ and between day-time and night-time periods for $\mathrm{CD1}(\mathrm{KW}=1117, \mathrm{df}=1, \mathrm{P}<0.001)$ but not for $\mathrm{CD} 2(\mathrm{KW}=743, \mathrm{df}=1, \mathrm{P}=0.86)$ and $\mathrm{CD} 3(\mathrm{KW}=835, \mathrm{df}=1, \mathrm{P}=0.55$, Fig. 4). All three trout monitored under CD1 showed high residence in a limited number of sectors (often including the feeder zone) particularly at night-time when residence frequency peaked to $80 \%$ in one sector. Trout under CD2 had an homogeneous distribution especially in the sectors included in the 
outer and medium circles both during day and night-time. However, trout $n^{\circ} 3$ showed more residence in one half of the outer circle, similar to CD1 fish. Space use patterns of trout under CD3 differed from the other two conditions by showing a higher residency in the inner circle.

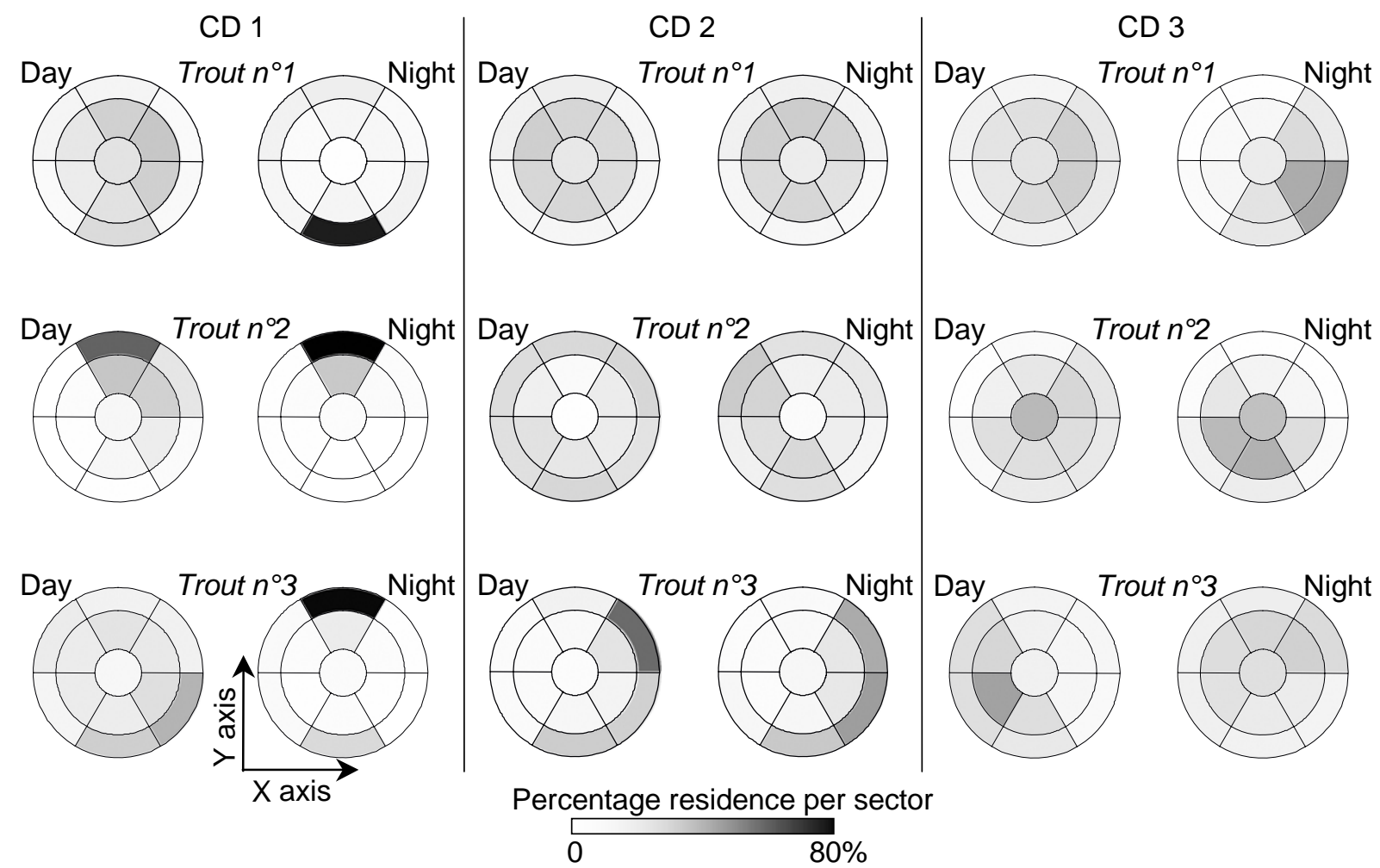

Figure 4 : Residence percentage per sector for each rainbow trout tracked under each culture condition (CD1, CD2 and CD3) for day-time and night-time periods.

\subsection{Activity patterns}

Activity levels between day-time during feeding and day-time without feeding were compared for each fish. Kruskal Wallis tests showed no difference between day-time with or without food (for $C D 1$, trout 1: $K W=43, P=0.20$; trout 2: $K W=53, P=0.50$; trout $3: \mathrm{KW}=56, P=$ 0.39; for $C D 2$ trout 1: $\mathrm{KW}=61, \mathrm{P}=0.85$; trout 2: $\mathrm{KW}=49, \mathrm{P}=0.56$; trout 3 : $\mathrm{KW}=71, \mathrm{P}=0.67$; and for $\mathrm{CD} 3$, trout 1: $\mathrm{KW}=69, \mathrm{P}=0.76$; trout 2: $\mathrm{KW}=92, \mathrm{P}=0.09$; trout 3: $\mathrm{KW}=64, \mathrm{P}=0.70$ ). Therefore, the statistical analysis were continued without this distinction.

Under CD1, activity levels showed significant differences and a higher diurnal than nocturnal activity for all individuals (Fig. 5 , trout 1 : $\mathrm{KW}=12.5 \mathrm{P}=0.002$, trout 2 : $\mathrm{KW}=13.9$ 
$\mathrm{P}=0.001$, trout 3: $\mathrm{KW}=12.6 \mathrm{P}=0.002$ ). Hourly distance moved ranged between $56 \mathrm{~m} \mathrm{~h}^{-1}$ and $187 \mathrm{~m} \mathrm{~h}^{-1}$ during the day and $49 \mathrm{~m} \mathrm{~h}^{-1}$ and $124 \mathrm{~m} \mathrm{~h}^{-1}$ at night.

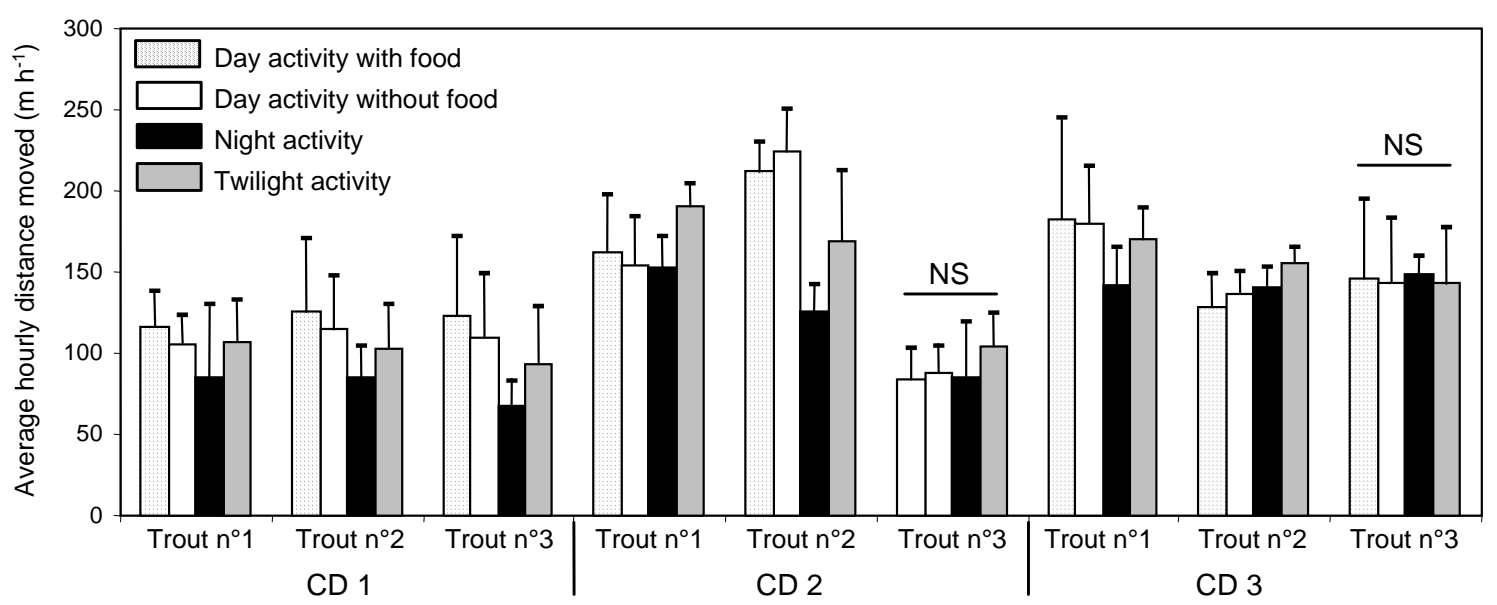

Figure 5 : Activity calculated for each rainbow trout under the three different culture conditions (CD1, CD2 and CD3). Average value and standard deviation is given for each component of the day (day-time during feeding, day-time without feeding, night-time and twilight). Non significant differences in activity patterns tested with a Kruskal Wallis test are shown above the bars (NS when $P_{k W}>0.05$ with $d f=3$ ).

Under CD2, all 3 fish behaved differently: trout $n^{\circ} 3$ showed a non significant pattern $(K W=3.0, P=0.213)$ similar in level to those observed for $C D 1$ fish. Trout $n^{\circ} 1$ was more twilightactive (KW=6.7 $\mathrm{P}=0.035)$ and trout $\mathrm{n}^{\circ} 2$ was mostly day-active ( $\mathrm{KW}=31.1, \mathrm{P}<0.001$; Fig. 5). Hourly distance moved had maximum values of $274 \mathrm{~m} \mathrm{~h}^{-1}$ during the day and $194 \mathrm{~m} \mathrm{~h}^{-1}$ at night, and minimum values of $59 \mathrm{~m} \mathrm{~h}^{-1}$ during the day and $47 \mathrm{~m} \mathrm{~h}^{-1}$ at night.

Under $C D 3$, trout $\mathrm{n}^{\circ} 1$ showed a clearly significant $(\mathrm{KW}=11.9, \mathrm{P}=0.003)$ day-active pattern (Fig. 5) when trout $\mathrm{n}^{\circ} 2$ was more nocturnal $(\mathrm{KW}=7.3, \mathrm{P}=0.026)$ and trout $\mathrm{n}^{\circ} 3$ showed a non significant pattern $(\mathrm{KW}=1.38, \mathrm{P}=0.500)$ due to an increase in night activity levels. Hourly distance moved oscillated between a maximum value of $258 \mathrm{~m} \mathrm{~h}^{-1}$ during the day and $192 \mathrm{~m} \mathrm{~h}^{-1}$ at night, and a minimum value of $99 \mathrm{~m} \mathrm{~h}^{-1}$ during the day and $96 \mathrm{~m} \mathrm{~h}^{-1}$ at night.

\section{Discussion}

In rainbow trout, the effects of stocking density have been shown to affect food conversion efficiency, nutritional condition, growth and to increase fin erosion (review in Ellis et al., 2002; Boujard et al., 2002) but does not appear to cause prolonged crowding stress. 
However, before its integrative actions, stocking density provokes alterations in fish behaviour (Schreck et al., 1997) with in particular density modifying social interactions within the group operation (Andrews, 1979). Thus, the most studied behavioural changes in salmonids are those including aggressive interactions such as feeding hierarchies (Alanärä and Brännäs, 1996) or territorial defence (Keenleyside and Yamamoto, 1962). Non aggressive interactions, activity, and swimming in particular, is another component of behavioural responses to stressors (Schreck et al., 1997) but seldom investigated in representative aquaculture structure (Kadri et al., 1991; Furevik et al., 1993; Huse and Holm 1993, Juell 1993, Juell and Westerberg, 1993, Kristiansen et al., 2004).

The present study was performed to test the feasibility of acoustic tracking under close to real aquaculture situation. The analysis of swimming activity variables for rainbow trout raised under different culture densities was successfully achieved. Results showed that the activity variables studied (trajectory complexity, space utilisation and activity rhythm) were altered by stocking conditions, and alterations were quantifiable.

Turning angle values showed that under CD1, fish were turning but an advance and reverse reflecting stationary positioning for long periods. Under CD2, inter-individual variability was observed with one fish showing circular swimming trajectories, one fish being stationary like CD1 fish and the third fish showing chaotic swimming like CD3 fish. Regular circular movements were observed during day-time whereas at night, displacements were poorly structured. Such circular activity is often observed in Atlantic salmon (Fernö et al., 1988; Juell and Westerberg, 1993) but far less reported for rainbow trout (Herbet, 1963; Phillips, 1985). According to the latter author, the appearance of this circular behaviour is closely related to the time of slack-water or associated with reduced current velocity $\left(<5 \mathrm{~cm} \mathrm{~s}^{-1}\right)$ independent of its direction. Under CD3, changes in swimming direction were numerous and resulted very likely from contacts with other fish. This possible explanation was strengthened by the observation of important fin damage for this treatment compared with the others (J.L. Gaignon, pers. Comm.). 
Preferred residence in the outer and medium circles were shown by fish under CD1 and CD2. These localisation include the feeder and the water inlet. No obvious link appeared between residence choice and the most shaded zone of the tank. Under CD3, a higher residency was observed in the inner circle likely induced by the crowding constraint. Thus, individual residency choices can be precisely measured using such method and when confronted with group positioning using echointegration (Juell, 1993; Juell and Westerberg, 1993; Bégout Anras et al. 2000), video monitoring (Kadri et al, 1991) or pit-tagging (Kristiansen et al., 2004), such information can be used as a behavioural indicators of some of the five freedoms of welfare (Anon. 1992, Ellis et al. 2002) including freedom to express normal behaviour (sufficient space, free access to food...).

In general, swimming activity of rainbow trout is low in intensity both under natural conditions, where they occupy a very limited territory (Scott and Crossman, 1973) and under low density rearing conditions in cages (Phillips, 1985). In the latter case, the fish did not show organised schooling displacements but slow swimming speeds with an important night-time swimming activity decrease (Sutterlin et al., 1979; Phillips, 1985). A similar activity rhythm was observed in the present study under low density (CD1). Under medium stocking density (CD2) activity levels were higher than under CD1 but decreased at night allowing the expression of a day-night rhythm significant for 2 fish out of 3 . A different situation was observed for the last group under high density (CD3) where swimming activity showed a high level of nocturnal activity which almost met the diurnal activity level. In this case, the individuals gradually lost the day-night activity rhythm under the pressure of culture conditions, reflecting an increasing constraint on activity which departed from the natural standard seen under less crowded conditions.

In order to correctly adapt to the conditions offered by its environment, fish swimming and foraging behaviours have to be sufficiently plastic to respond to new environmental constraints (Dill, 1983). One of the plastic components of behaviour is the level and timing of activity and our results showed that culture conditions imposed on fish influenced activity and 
induced a high level of activity and a loss of day-night rhythm under the highest environmental constraint. The associated effects on metabolism, increased swimming activity, swimming trajectory complexity and fin abrasion, suggest a steady increase in energy demand in relation to culture conditions (Webb, 1991; Tang and Boisclair, 1993; Trudel and Boisclair, 1993). A direct measure of energetic cost associated with stocking density has recently been achieved through two different experimental approaches. In a study conducted by Lefrançois et al. (2001), no significant variations of routine metabolic rate were detected between 25, 65 and $100 \mathrm{~kg} \mathrm{~m}^{-3}$ using respirometry experiments. In the second study, which measured the variation in swimming activity with increasing stocking density (Cooke et al., 2000), oxygen consumption estimates rose with increasing density treatments. The results of Cooke et al. (2000) would be more in support of our observations on fish activity increase and that of Krohn and Boisclair (1994), who attributed a significant and increasing energetic cost to the swimming trajectory complexity. Indeed, growth and feed intake were affected by fish density but not feed efficiency body composition and nutrient retention (parallel study conducted by Boujard et al., 2002). They concluded that food accessibility was the main factor responsible for the observed densityrelated decrease in growth and that trout adapted to crowding by reducing food intake. This is consistent with our observations of a lesser oriented swimming under the highest environmental constraint.

Authors acknowledge that high stocking density elicits density-dependent behavioural changes (Vijayan and Leatherland, 1988; Ellis et al. 2001; Kristiansen et al., 2004), these changes are mostly attributed to alterations in social dominance hierarchies and to aggressive and or disturbing interactions, whether lowered or enhanced. Such alterations remain difficult to measure under true aquaculture conditions but, as the present study has shown, constraints associated with culture conditions can be remotely evaluated through precise in situ assessment of non-aggressive activity variables which are sensitive to environmental conditions imposed on fish. 


\section{Acknowledgements}

We gratefully acknowledge J. Aubin, L. Labbé and L. Lebrun from the research station (SEMII) for their valuable assistance during the experimental period. This work was partially funded by the « Fédération Française d'Aquaculture » and the « Ministère de l'Agriculture et de la Pêche, Direction Générale de l'Alimentation (DGAL) ». This study was conducted under the approval of the Animal Care Committee of France under the official licence of J.P. Lagardère $\left(n^{\circ} 02526\right)$. We thank three anonymous referees for commenting on the manuscript.

\section{References}

Alanärä, A., Brännäs, E. 1996. Dominance in demand-feeding behaviour in Arctic charr and rainbow trout: the effect of stocking density. J. Fish Biol. 48, 242-254.

Andrews, R.V., 1979. The physiology of crowding. Comp. Biochem. Phys. 63A, 1-6.

Anon., 1992. FAWC updates the Five Freedoms. Veterinary Record 131, 357.

Baras, E., 1992. Etude des stratégies d'occupation du temps et de l'espace chez le barbeau fluviatile, Barbus barbus (L.). Cahiers d'Ethologie 12, 125-442.

Baras, E., Lagardère, J. P., 1995. Fish telemetry in aquaculture : review and perspectives. Aquacult. Int. 3, 77-102.

Bégout Anras, M.L., Lagardère, J.P., 1998. Variabilité météorologique : conséquences sur l'activité natatoire d'un poisson marin. C. R. Acad. Sci.III-Vie 321, 641-648.

Bégout Anras, M.L., Lagardère, J.P., Lafaye, J.Y., 1997. Diel activity rhythm of seabass tracked in a natural environment: group effects on swimming patterns and amplitudes. Can. J. Fish. Aquat. Sci. 54, 162-168.

Bégout Anras, M.L., Kadri, S., Juell, J.E., Hansen, T., 2000. Measuring individual and group swimming behaviour under production densities: test of a 3D multiple fish acoustic positioning system in a sea cage. In Moore A., Russell I. (Eds), Advances in fish telemetry. CEFAS Lowesoft publication, pp 75-78.

Boujard, T, Labbé, L, Aupérin, B, 2002. Feeding behaviour, energy expenditure and growth of rainbow trout in relation to stocking density and food accessibility. Aquac. Research 33, $1233-1242$. 
Bridger, C. J., Booth, R. K., 2003. The effects of biotelemetry transmitter presence and attachment procedures on fish physiology and behaviour. Reviews in Fisheries Science 11, 13-34.

Cooke, S.J., Chandroo, K.P., Beddow, T.A., Moccia, R.D., McKinley, R.S., 2000 Swimming activity and energetic expenditure of captive rainbow trout Oncorhynchus mykiss (Walbaum) estimated by electromyogram telemetry. Aquac. Res. 31, 495-505.

Dantzer, R., 1995. Confort et bien-être des animaux en élevage intensif. Point Vétérinaire 26, $1027-1034$.

Dill, L.M., 1983. Adaptive flexibility in the foraging behaviour of fishes. Can. J. Fish. Aquat. Sci. 40, 398-408.

Ellis, T., B. North, A. P., Scott, N. R. Bromage, M. Porter, Gadd D., 2002. The relationships between stocking density and welfare in farmed rainbow trout. J. Fish Biol. 61, 493-531.

Fernö, A., Furevik, D., Huse, I., 1988. A multiple approach to behaviour studies of salmon reared in marine net pens. International Council for the Exploration of the Sea, Mariculture committee, C.M., 1-15.

Furevik, D.M., Bjordal, A., Huse, I., Fernö, A, 1993. Surface activity of Atlantic salmon (Salmo salar L.) in net pens. Aquaculture 110, 119-128

Herbert, D.W.M., 1963. Reversal of direction of swimming by rainbow trout (Salmo gairdnerii Richardson) on stopping a current of water. Anim. Behav. 11, 2-3.

Huse, I., Holm, J. C., 1993. Vertical distribution of Atlantic salmon (Salmo salar) as a function of illumination. J. Fish Biol. 43, 147-156.

Juell, J. E., 1993. Managing the behaviour and growth of Atlantic salmon (Salmo salar L.) in sea cages. PhD Thesis, University of Bergen, Norway, 108 pp.

Juell, J.E., Westerberg, H. , 1993. An ultrasonic telemetric system for automatic positioning of individual fish used to track Atlantic salmon (Salmo salar L.) in a sea cage. Aquacult. Eng. 12, 1-18.

Kadri, S., Metcalfe, N.B., Huntingford, A, Thorpe, J.E., 1991. Daily feeding rhythms in Atlantic salmon in sea cages. Aquaculture 92, 219-224.

Keenleyside, M.H.A., Yamamoto, F.T., 1962. Territorial behaviour of juvenile Atlantic salmon 
(Salmo salar L.). Behaviour 19, 139-169.

Kristiansen, TS, Fernö, A, Holm, JC, Privitera, L, Bakke, S, Fosseidengen, JE, 2004. Swimming behaviour as an indicator of low growth rate and impaired welfare in Atlantic halibut (Hippoglossus hippoglossus L.) reared at three stocking densities. Aquaculture 230, $137-151$.

Krohn, M.M., Boisclair, D., 1994. Use of a stereo-video system to estimate the energy expenditure of free-swimming fish. Can. J. Fish. Aquat. Sci. 51, 1119-1127.

Lagardère, J.P., Ducamp, J.J., Favre, L., Mosneron-Dupin, J., Sperandio, M., 1990. A method for the quantitative evaluation of fish movements in salt ponds by acoustic telemetry. $\mathrm{J}$. Exp. Mar. Biol. Ecol. 141, 221-236.

Lefrançois, C., Claireaux, G., Mercier, C., Aubin, J., 2001. Effect of density on the routine metabolic expenditure of farmed rainbow trout (Oncorhynchus mykiss). Aquaculture $195,269-277$

Olla, B.L., Pearson, W.H., Studholme, A.L., 1980. Applicability of behavioral measures in environmental stress assessment. Rapports et Procés-verbaux des Réunions du Conseil International pour l'Exploration de la Mer 179, 162-173.

Phillips, M.J., 1985. Behaviour of rainbow trout, Salmo gairdneri Richardson, in marine cages. Aquacult. Fish. Management 16, 223-232.

Ross, M.J., McCormick, J.H., 1981. Effects of external radio transmitters on fish. Progr. Fish Cult. $43,67-72$.

Scherer, E., 1992. Behavioural responses as indicators of environmental alterations: approaches, results, developments. J. Appl. Ichthyol. 8, 122-131.

Schreck, C.B., 1990. Physiological, behavioral, and performance indicators of stress. American Fisheries Society Symposium 8, 29-37.

Schreck, C.B., Olla B., L., Davis, M.W., 1997. Behavioral responses to stress. In Iwama, G.K.; Pickering, A.D.; Sumpter, J.P.; Schreck, C.B. (Eds), Fish stress and Health in Aquaculture. Cambridge University Press, Cambridge, pp. 145-170

Scott, W.B., Crossman, E.J., 1973. Freshwater fishes of Canada. B. Fish. Res. Board Can. 184, 966 pp. 
Sutterlin, A.M., Jokola, K.J., Holte, B., 1979. Swimming behavior of salmonid fish in ocean pens. J. Fish. Res. Board Can. 36, 948-954.

Tang, M., Boisclair, D., 1993. Influence of the size of enclosures on the swimming characteristics of juvenile brook trout (Salvelinus fontinalis). Can. J. Fish. Aquat. Sci. 50, 1786-1793.

Trudel, M., Boisclair, D., 1993. An in situ evaluation of the day-to-day variation in the quantity of food consumed by fish. Can. J. Fish. Aquat. Sci. 50, 2157-2165.

Vijayan, M.M., Leatherland, J.F., 1988. Effect of stocking density on the growth and stressresponse in brook charr, Salvelinus fontinalis. Aquaculture 75, 159-170.

Webb, P.W., 1991. Composition and mechanics of routine swimming of rainbow trout, Oncorhynchus mykiss. Can. J. Fish. Aquat. Sci.48, 583-590. 